PERCURSOS DE UMA DISCIPLINA EM CONSTRUÇẪO: CURRÍCULO E IDENTIDADE DO ENSINO DE SOCIOLOGIA NO RIO DE JANEIRO Marcia Menezes Thomaz Pereira

\title{
PERCURSOS DE UMA DISCIPLINA EM CONSTRUÇÃO: CURRÍCULO E IDENTIDADE DO ENSINO DE SOCIOLOGIA NO RIO DE JANEIRO
}

\author{
PATHWAYS OF A DISCIPLINE UNDER CONSTRUCTION: CURRICULUM \\ AND IDENTITY OF SOCIOLOGY EDUCATION IN RIO DE JANEIRO
}

Marcia Menezes Thomaz Pereira

\section{RESUMO}

A proposta deste trabalho é apresentar um resgate da história do ensino de Sociologia na rede pública de educação do estado do Rio de Janeiro através da observação das suas propostas curriculares, com o objetivo de apontar 0 currículo, e o modo como ele é produzido, divulgado, apropriado e realizado por professores e professoras regentes, na sua relação cotidiana com a disciplina, como um importante elemento para pensarmos a configuração da identidade da Sociologia no âmbito escolar. Quais são e como são ensinados os conteúdos de Sociologia, quais os sentidos são atribuídos ao seu ensino e os lugares que a disciplina vem ocupando estão estreitamente relacionados a sua trajetória dentro do sistema educacional e revelam alguns dos desafios e das possibilidades para o seu reconhecimento e valorização, bem como sua consolidação, na educação básica. Importa ao resgate desta trajetória específica permitir demarcar a institucionalidade desta disciplina hoje na rede pública do estado do Rio de Janeiro e apresentar uma faceta do que vem sendo a Sociologia enquanto disciplina escolar. Para tanto, serão problematizadas as peças curriculares oficiais de Sociologia da Secretaria de Estado de Educação (SEEDUC-RJ), publicadas a partir de 2006. Contudo, a ênfase recairá sobre a atual proposta curricular, o Currículo Mínimo, e suas 
PERCURSOS DE UMA DISCIPLINA EM CONSTRUÇÃO: CURRÍCULO E IDENTIDADE DO ENSINO DE SOCIOLOGIA NO RIO DE JANEIRO Marcia Menezes Thomaz Pereira

implicações políticas e pedagógicas. A organização desta trajetória tem como fonte trabalhos acadêmicos e documentos oficiais, assim como os relatos de dez professores e professoras regentes na rede pública de ensino, entrevistados durante a pesquisa de mestrado desenvolvida pela autora desta comunicação.

Palavras-chave: Ensino de Sociologia. Currículo. Identidade.

\section{ABSTRACT}

The purpose of this paper is to present a brief summary of the history of Sociology teaching in the public education network of the state of Rio de Janeiro through the observation of its curricular proposals with the aim of pointing out the curriculum, and how it is produced, received, appropriated and carried out by teachers in their day-today relationship with the discipline, as an important element to think about the configuration of the identity of Sociology in the school context. What are and how are the contents of Sociology taught, what are the meanings attributed to its teaching and the places that the discipline is occupying are closely related to its trajectory within the educational system and reveal some of the challenges and possibilities for their recognition and appreciation, as well as their consolidation, in basic education. It is important to rescue this specific trajectory to make it possible to demarcate the institutionality of this discipline today in the public network of the state of Rio de Janeiro and present a facet of what Sociology has been doing as a school discipline. Therefore, the official curricular pieces of Sociology of the State Secretariat of Education (SEEDUC-RJ), published as of 2006. However, the emphasis will be on the current curricular proposal, the Minimum Curriculum, and its political and pedagogical implications. The organization of this trajectory has as its source academic papers and official documents, as well as the reports of ten teachers and teachers in the public school network, interviewed during the master's research developed by the author of this communication. 
PERCURSOS DE UMA DISCIPLINA EM CONSTRUÇÃO: CURRÍCULO E IDENTIDADE DO ENSINO DE SOCIOLOGIA NO RIO DE JANEIRO Marcia Menezes Thomaz Pereira

Keywords: Teaching of Sociology. Curriculum. Identity

\section{INTRODUÇÃO}

Este texto apresenta um breve resumo das propostas curriculares oficiais de Sociologia da Secretaria de Estado de Educação do Rio de Janeiro (SEEDUC), com destaque à peça curricular vigente, o Currículo Mínimo, buscando mostrar como o currículo e o modo como é ele produzido, divulgado, apropriado e realizado por professores e professoras regentes, na sua relação cotidiana com a disciplina, podem ser importantes elementos para pensarmos a configuração da identidade da disciplina Sociologia na educação básica.

O reconhecimento de quais são e a problematização de como são ensinados os conteúdos de Sociologia são aspectos que estão estreitamente relacionados a sua trajetória dentro do sistema educacional e podem revelar alguns dos desafios e das possibilidades para a valorização e a consolidação da disciplina neste nível de ensino.

Para cumprir essa tarefa, utilizo alguns dados e análises resultantes da pesquisa e trabalho de campo realizados em função da dissertação de Mestrado em Ciências Sociais, defendida pela autora deste texto, intitulada "A construção social da identidade da Sociologia como disciplina escolar - Que Sociologia é essa?". Tal trabalho envolveu, além de pesquisa documental, entrevistas semi-estruturadas com gestores da SEEDUC e com dez professores e professoras da rede pública de ensino, lotados em escolas pertencentes à Regional Administrativa e Pedagógica Metropolitana III, que abarca escolas da zona norte da cidade do Rio de Janeiro. Através destas entrevistas, pôde-se revelar dados interessantes sobre a trajetória da disciplina na rede pública ao serem narradas histórias pessoais e profissionais. A esses dados, outros atualizados, referentes ao ano de 2016, foram somados. 


\section{AS PROPOSTAS CURRICULARES OFICIAIS DE SOCIOLOGIA DA SECRETARIA DE ESTADO DE EDUCAÇÃO DO RIO DE JANEIRO: TRAJETÓRIA E IDENTIDADE}

Apesar de incluída "como disciplina obrigatória nos currículos do $2^{\circ} \mathrm{grau}$, da rede pública e privada, em todo o território do Estado do Rio de Janeiro"

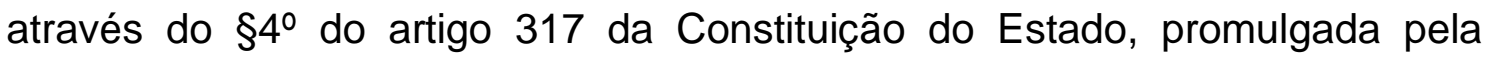
Assembleia Legislativa, em 05 de outubro de 1989, as propostas curriculares da SEEDUC para a Sociologia expressam em certa medida algumas das tensões que essa disciplina vem encontrando em seus caminhos na educação básica. O primeiro documento oficial do estado que buscou organizar um conjunto de conteúdo a ser trabalhado na escola básica, cuja ciência de referência eram as Ciências Sociais, data de 1990. Nesse ano, uma comissão especial designada pelo Conselho Estadual de Educação do Rio de Janeiro, promoveu dois encontros (o primeiro no mês de maio e o segundo em outubro) sobre a introdução da Sociologia no $2^{\circ}$ grau, com o objetivo discutir e formular uma normatização para a implantação da disciplina, uma vez que

“(...) considerou essencial buscar subsídios junto aos diferentes setores da sociedade diretamente vinculados ao problema; para tanto achou por bem congregar especialistas integrantes dos diversos segmentos do sistema de ensino para debater questões de conteúdo, metodologia, formação de professores, impacto na grade curricular, visando gerar um posicionamento democrático, fruto de opiniões e pensamentos". [De modo que] $O$ encontro constou de mesas redondas com palestras de especialistas da área, trabalhos de grupo ou GTs, plenárias para apresentação das conclusões dos grupos. A participação foi mais que significativa. Além da Associação Profissional dos Sociólogos do Estado do Rio de Janeiro - APSERJ, estiveram presentes o Conselho Estadual de Educação - CEE/RJ, Secretaria Estadual de Educação - SEE/RJ, Coordenadoria de Supervisão Educacional - COSE-E, Coordenadoria de 2o Grau COSG-E, Departamento de Educação, Gabinete da Secretaria, Núcleos de Educação Comunitária - NECs, Escolas Particulares de Ensino Médio, Sindicato de Professores - SEPE, quatro Universidades e três Faculdades. Com destaque para a Universidade do Estado do Rio de Janeiro - UERJ e Universidade Federal Fluminense - UFF, através de seus Departamentos de Ciências Sociais (CONTERATO, 2009, p.02) 
PERCURSOS DE UMA DISCIPLINA EM CONSTRUÇÃO: CURRÍCULO E IDENTIDADE DO ENSINO DE SOCIOLOGIA NO RIO DE JANEIRO Marcia Menezes Thomaz Pereira

Como resultado desses encontros, foi emitido um documento final que serviria de subsídio para o Conselho Estadual de Educação tratar as questões em torno da implantação da lei de obrigatoriedade da Sociologia no $2^{\circ}$ grau. No que dizia respeito aos objetivos da disciplina nesse nível de ensino, o documento assinala a sua contribuição na formação do aluno na construção e exercício da cidadania, além de contribuir para recuperar a dimensão humanística do ensino e fornecer instrumental de reflexão e análise crítica da realidade social.

Em relação à carga horária e sua disposição na grade curricular, o documento aponta para a necessidade de a disciplina ter uma carga horária mínima de duas horas/aula semanais, em cada uma das séries do $2^{\circ}$ grau. Contudo, realça o caráter mínimo de tal proposta contando que a mesma "possa ser ampliada, conforme as disponibilidades existentes tanto na rede pública, quanto nas escolas particulares, a fim de buscar implantar as quatro horas semanais, consideradas adequadas para um trabalho de natureza formadora e não apenas informadora" (CONTERATO, 2006, p.56).

$\mathrm{O}$ documento apresenta também algumas propostas metodológicas para - ensino de Sociologia, sugerindo, entre outras coisas, uma relação interdisciplinar da Sociologia com as demais disciplinas, o exercício da observação participante, com o intuito de "levar os alunos a observarem a realidade que os circunda e descrevê-la como um dos seus participantes" (CONTERATO, 2006, p.57), assim como refletir sobre os aspectos da realidade observada, relacionando-os ao contexto social mais amplo e ao universo cotidiano dos alunos.

É com essa orientação que o documento apresenta um conteúdo programático com cinco tópicos - sem proposta de distribuição e sequenciamento -, que acreditamos indicarem um conteúdo mínimo ou essencial da Sociologia no $2^{\circ}$ grau. São eles: I) Introdução, onde se propõe uma apresentação crítica das relações sociais que constituem o universo histórico do aluno e da Sociologia e seu papel analítico-crítico e transformador; II) A Base Material da Sociedade, cujo conteúdo se dedica ao estudo do modo 
PERCURSOS DE UMA DISCIPLINA EM CONSTRUÇÃO: CURRÍCULO E IDENTIDADE DO ENSINO DE SOCIOLOGIA NO RIO DE JANEIRO Marcia Menezes Thomaz Pereira

de produção capitalista e seu funcionamento, atentando para a observação das condições materiais de vida e de trabalho do universo do aluno; III) Condições Não Materiais de Existência, que subdivide-se em dois tópicos: a) Política e Ideologia, que abrange as dimensões políticas e econômicas nas relações entre Estado e Sociedade, com ênfase para a relação entre o Estado e as classes sociais no Brasil e a conjuntura atual; e b) Cultura e Ideologia, no qual propõe destacar a relação da ideologia com a moral, a arte, a religião, a filosofia, a ciências, os valores, etc. A relação entre cultura popular e cultura de massa, e a cultura institucionalizada e a contestação cultural, principalmente, os movimentos contestatório no Brasil (o movimento negro, indígena, feminino, a contracultura, etc.); IV) Organização e Transformação Social, que busca apresentar algumas formas de participação política no processo de transformação social; as teorias conservadores, reformistas e revolucionárias de mudança social; o desenvolvimento das forças produtivas e as relações de produção, além de tratar dos partidos políticos e as correntes políticas no Brasil e os movimentos sociais brasileiros; V) Instituições Sociais, que propõe uma análise crítica das instituições sociais a partir da relação entre ideologia e as instituições sociais, dentre as quais destaca a família, a escola, os meios de comunicação e a religião.

Apesar de todos esses esforços, muitas das demandas e proposições que apresentam tal documento podem ser observadas ainda hoje, mais de vinte anos depois, nas arenas, organizadas ou não, de discussão sobre o ensino de Sociologia. O cumprimento da obrigatoriedade da disciplina na rede pública se deu nos anos seguintes à promulgação da lei conformando um cenário repleto de obstáculos que se desdobrariam de diversas maneiras, tanto em termos materiais como simbólicos, sobre os professores e as professoras de Sociologia da rede pública de ensino. A reduzida carga horária que assumiu a disciplina e a permissão a professores não licenciados em Sociologia ou Ciências Sociais para ministrá-la exemplificam alguns dos seus desafios.

A consequência dos impasses colocados pela legislação, dada a imprecisão na sua normatização somada ao pouco interesse político do 
PERCURSOS DE UMA DISCIPLINA EM CONSTRUÇÃO: CURRÍCULO E IDENTIDADE DO ENSINO DE SOCIOLOGIA NO RIO DE JANEIRO Marcia Menezes Thomaz Pereira

governo do estado na questão, pôde ser observada através de irregularidades na implantação da disciplina nas escolas ao longo da década de 1990 e início dos anos 2000, no que se referem, principalmente, ao (não) efetivo cumprimento da obrigatoriedade e seus efeitos, especialmente aqueles relativos à inserção dos professores e da disciplina nas escolas e os espaços que a Sociologia começaria a ocupar a partir deste momento. Muitos são os relatos sobre professores sem licenciatura plena na área ministrando a disciplina, sobre mudanças de matriz curricular que ora apresenta a disciplina com dois tempos em uma série, ora com apenas um tempo em outra série, impedindo um trabalho regular dos professores, escolas que não ofereciam a disciplina, entre outros.

No entanto, a partir de meados dos anos 2000 um novo quadro começa a se desenhar. Se, de acordo com a periodização elaborada por Santos (2002; 2004), a história da intermitente presença da Sociologia na escola básica, em um cenário nacional, pode ser observada em três períodos, quais sejam um primeiro que vai de 1891 a 1941, de institucionalização da sociologia no país via ensino na escola secundária; um segundo, que vai de 1942 a 1981, que representa a retirada da Sociologia como disciplina obrigatória do currículo escolar; e, finalmente, um terceiro período, de reinserção gradativa da sociologia no Ensino Médio, que começa em 1982 e se estende, em sua análise, até 2001, podemos sinalizar, a partir desta periodização, um quarto período, que seria o de afirmação da Sociologia como disciplina escolar. Tal período começa a se clarear em 2006 com o parecer da Câmara de Educação Básica do Conselho Nacional de Educação, o Parecer CNE/CEB n³8/2006, favorável à inclusão obrigatória da Sociologia e Filosofia no currículo do Ensino Médio, e ganha contornos mais definidos com a aprovação, em 2008, da Lei Federal $n^{\circ}$ 11. 684. Essas alterações de ordem legal, no âmbito nacional, têm efeitos variados nos estados, tanto sobre as escolas e secretarias de educação, como sobre as universidades, de acordo com o estágio de discussão da matéria em cada localidade. No Rio de Janeiro, observamos uma 
PERCURSOS DE UMA DISCIPLINA EM CONSTRUÇÃO: CURRÍCULO E IDENTIDADE DO ENSINO DE SOCIOLOGIA NO RIO DE JANEIRO Marcia Menezes Thomaz Pereira

série de eventos que caminham nesse sentido de afirmação - embora nem sempre esse caminho seja em uma linha reta, como veremos a seguir.

No ano de 2004, a SEEDUC realizou um novo e grande concurso público que contemplou todas as disciplinas, inclusive, a Sociologia, com distribuição de vagas para diferentes regiões do estado. Também nesse mesmo ano, a Secretaria iniciou um processo de elaboração de propostas curriculares destinado a todas as disciplinas. Tal processo teve continuidade durante o ano de 2005 e culminância em janeiro de 2006, com a publicação de um documento intitulado Reorientação Curricular.

A Reorientação Curricular, proposta pela Secretaria, apresenta as disciplinas divididas de acordo com as áreas de conhecimento. A Sociologia encontra-se no documento Reorientação Curricular: Ciências Humanas, no qual estão expostos cinco eixos temáticos com seus respectivos conteúdos programáticos, assim como as competências e habilidades que devem ser adquiridas pelos estudantes, propostas metodológicas, as possíveis interfaces com as demais disciplinas e sugestões de sites e bibliografia para os professores. De acordo com a sua apresentação, tal proposta é resultado de um trabalho coletivo entre professores da rede pública do estado do Rio de Janeiro e professores universitários envolvidos com a formação docente, com o objetivo de "nortear o processo de elaboração e construção do planejamento político pedagógico e do currículo das escolas da rede estadual pública do Estado do Rio de Janeiro" (RIO DE JANEIRO, 2006, p. 15). Ou seja, através dele os professores teriam as bases para construir não apenas o plano de curso para as suas turmas naquele ano, mas também o projeto político pedagógico das escolas.

Seu processo de elaboração ocorreu através do envio de um texto preliminar encaminhado às escolas da rede pública, em novembro de 2004, o qual foi debatido com os professores em reuniões de trabalho promovidas pela SEEDUC entre os dias 27 de novembro e quatro de dezembro de 2004 (ou seja, em apenas uma semana e no fim do ano letivo). Tal processo de construção, afirma o documento, teve continuidade através de reuniões nas 
PERCURSOS DE UMA DISCIPLINA EM CONSTRUÇÃO: CURRÍCULO E IDENTIDADE DO ENSINO DE SOCIOLOGIA NO RIO DE JANEIRO Marcia Menezes Thomaz Pereira

escolas, do envio de sugestões e críticas pelos professores, e a consequente análise e incorporação destas sugestões pelas equipes dos autores. Em seguida, já em fevereiro de 2005, o documento foi reapresentado às escolas.

Assim, durante o ano letivo de 2005, foram realizadas mais discussões sobre a proposta, que, ao longo do ano, foram obtendo outra dimensão, assumindo o caráter de um curso de atualização envolvendo mais professores. Durante este curso, o documento foi rediscutido, e cadernos didáticos de cada disciplina foram elaborados pelos professores. Além de refletirem sobre o papel de cada disciplina que compõe as diferentes áreas de conhecimento no processo educativo, os documentos trazem, sobretudo, orientações de conteúdo e de metodologias, oriundas da troca de experiências entre os professores da rede e os da universidade responsáveis pela redação daquele documento.

A Reorientação Curricular de Sociologia, cuja autoria é assinada pelas professoras Monica Grin (Departamento de História/IFCS/UFRJ), Sandra M. Rodrigues da Rocha (Colégio Estadual Antônio Prado Júnior) e Maria Manuela Alves Maia (Colégio Estadual Engenheiro Bernardo Sayão), contou também com um caderno de Materiais Didáticos desenvolvido por 13 professores de diferentes colégios estaduais.

O terceiro documento curricular oficial de Sociologia para a rede pública foi lançado no ano de 2010. Junto às demais disciplinas, o currículo compunha o projeto Proposta Curricular: Um Novo Formato. Tal projeto foi resultado de uma releitura das Reorientações Curriculares, de 2006, sob orientação geral das professoras Ana Canen (UFRJ) e Giseli Pereli de Moura Xavier (UniverCidade/UFRJ) com o apoio de professores de Sociologia, Filosofia e História regentes na rede, os quais deveriam avaliar e validar o documento. Em acordo com a matriz curricular para este ano letivo, que inaugurou a inclusão da Sociologia em todas as séries do Ensino Médio, o documento apresentou a divisão do conteúdo a ser ministrado para cada série do Ensino Médio regular, bimestre por bimestre, a partir da organização pedagógica em habilidades e competências. 
PERCURSOS DE UMA DISCIPLINA EM CONSTRUÇÃO: CURRÍCULO E IDENTIDADE DO ENSINO DE SOCIOLOGIA NO RIO DE JANEIRO Marcia Menezes Thomaz Pereira

A "Proposta Curricular: Um Novo Formato" teve origem na necessidade, por parte da SEEDUC, de revisão dos currículos até então prescritos para as disciplinas da rede, com o objetivo de facilitar a sua operacionalização na sala aula. Além disso, esperava-se, com essa releitura, uma normatização mais rigorosa dos conteúdos para atender a duas demandas que a Secretaria se colocava à época: a primeira dizia respeito a um projeto vislumbrado na gestão da então secretária Tereza Porto, chamado Casa do Professor, que visava construir um centro de formação continuada e de apoio teórico e pedagógico aos professores da rede; a segunda era dar início a um processo de avaliação e controle do conteúdo que vinha sendo trabalhado em sala de aula como meio para melhor atender, sobretudo, às matrizes de referência dos exames nacionais e estaduais.

A despeito do projeto Casa do Professor não ter se concretizado e, em meados de 2010, a secretária Tereza Porto ter sido substituída pelo o economista Wilson Risolia, o currículo de Sociologia, bem como os das demais disciplinas, entrou em vigência na rede neste ano. Tal currículo, embora não tenha tido ampla divulgação entre os professores, não impactando de forma significativa seus trabalhos, gerou reação de intelectuais, veículos da grande imprensa e da própria Sociedade Brasileira de Sociologia, que se manifestou em nota pública, no mês de março, com duras críticas à proposta, como podemos ver no trecho destacado abaixo:

[...] a Sociedade Brasileira de Sociologia criou em seu Congresso de 2005 a Comissão de Ensino Médio. Desde então, esta Comissão passou a centralizar as iniciativas dos estados, realizando encontros e congressos com o propósito de contribuir para práticas do ensino de Sociologia, tendo em vista a preocupação com sua qualidade. Nessa direção, hoje podemos afirmar que temos acumulado conhecimento sobre a temática, autorizando-nos a apoiar a elaboração de propostas curriculares em vários estados brasileiros. Por esta razão, vimos manifestar nossa preocupação com a proposta curricular de Sociologia apresentada pela Secretaria Estadual de Educação do Rio de Janeiro, na medida em que esta sugere certos conteúdos temáticos que consideramos irrelevantes para o ensino de Sociologia no ensino médio, apresenta como conceitos certos termos não identificados no arcabouço teórico e conceitual advindo das 
PERCURSOS DE UMA DISCIPLINA EM CONSTRUÇÃO: CURRÍCULO E IDENTIDADE DO ENSINO DE SOCIOLOGIA NO RIO DE JANEIRO Marcia Menezes Thomaz Pereira

Ciências Sociais e se fundamenta em uma concepção prescritiva ou normativa do ensino de Sociologia.

A negativa repercussão do currículo de Sociologia foi apenas uma expressão dos problemas do projeto Proposta Curricular: Um Novo Formato, que, vale destacar, já nasceu sinalizando para a realização de um projeto mais consistente, nos termos da própria SEEDUC, de proposta curricular. Diante disso, a Secretaria, ainda no ano de 2010, iniciou um novo processo. Desta vez, com o objetivo de reformular os currículos da rede partindo de novas equipes de elaboração e coordenação que estão resumidos na proposta curricular em vigência, o projeto Currículo Mínimo.

\section{o CURRÍCULO MÍNIMO}

Lançada no final do ano 2011, a proposta curricular vigente é um desdobramento de uma primeira versão que fora apresentada para toda a rede no início desse mesmo ano e da qual a autora deste texto fez parte como integrante da equipe de elaboração junto a mais cinco professores da rede estadual.

Em outubro de 2010, a SEEDUC organizou equipes pedagógicas formadas por professores da própria Secretaria para a elaboração de propostas curriculares que pudessem equiparar toda a rede pública em termos de conteúdo. Tal iniciativa visava produzir programas para cada disciplina do Ensino Médio, normatizando um conjunto de currículos mínimos que estivessem não apenas de acordo com as legislações vigentes e as demandas atuais do ensino, mas também em conformidade com as matrizes curriculares dos principais exames nacionais e estaduais.

O pressuposto fundamental para a possibilidade deste nivelamento era de que os currículos seriam formulados a partir da experiência de professores da rede, o que, naquele momento, era garantido - ainda que de modo bastante limitado - não apenas pela composição das equipes, mas pela realização de 
PERCURSOS DE UMA DISCIPLINA EM CONSTRUÇÃO: CURRÍCULO E IDENTIDADE DO ENSINO DE SOCIOLOGIA NO RIO DE JANEIRO Marcia Menezes Thomaz Pereira

consultas via Internet aos docentes, através do sítio eletrônico Conexão Professor, e de uma audiência pública previstas para este processo.

A equipe de Sociologia foi composta por seis professores de diferentes localidades e regiões do estado, com perfis e experiências variadas. Tanto os membros das equipes quanto suas coordenações foram convidados pela Secretaria para a execução deste trabalho a partir de uma rede de indicações pessoal e profissional. Vale ressaltar que, ao contrário dos currículos de Sociologia apresentados pela SEEDUC em 2006 e 2010, para o currículo de 2011 houve a preocupação de compor uma equipe formada somente por professores de Sociologia com formação em Ciências Sociais, isto é, bacharelado e licenciatura plena em Ciências Sociais.

A despeito da explícita orientação da Secretaria para que a elaboração dos currículos se pautasse na organização em habilidades e competências, sua confecção ficou sob total responsabilidade das equipes montadas pela SEEDUC, desde a seleção dos conteúdos pertinentes à formação na Educação Básica, até sua organização e distribuição e sequenciamento em anos e bimestres, garantindo-se relativa autonomia de trabalho. Sobre esse ponto, a equipe de Sociologia julgou que a estrutura de um currículo organizado em competências e habilidades a descaracterizaria, entrando na contramão do movimento de afirmação e configuração da sua identidade na escola básica.

Entendia-se que o currículo assim organizado tende a suprimir os conteúdos disciplinares baseados em conceitos e, por consequência, as próprias disciplinas. Primeiro porque, nesta perspectiva, o ensino passa a ser definido pela produção de competências verificáveis em situações e tarefas específicas que os alunos deverão ser capazes de adquirir. Observa-se principalmente o resultado do processo educativo. Segundo porque as disciplinas começam a se diluírem, adequando-se às diretrizes nacionais que defendem uma organização curricular por áreas de conhecimento. Deste modo, a aprendizagem de competências e habilidades ganha um caráter geral e pragmático, que visa a possibilitar maior assimilação e adaptação às mudanças constantes do mundo contemporâneo. 
PERCURSOS DE UMA DISCIPLINA EM CONSTRUÇÃO: CURRÍCULO E IDENTIDADE DO ENSINO DE SOCIOLOGIA NO RIO DE JANEIRO Marcia Menezes Thomaz Pereira

Uma leitura crítica do modelo organizado em habilidades e competências o define como gerador de um currículo esvaziado e que limita tanto a compreensão do processo histórico e social de construção do conhecimento científico, quanto do desenvolvimento intelectual dos estudantes. Esta crítica se baseia na afirmação de que somente os conteúdos formulados a partir de conceitos e teorias das ciências de referência possibilitariam uma leitura crítica, criativa e engajada do mundo (RAMOS, 2009; YOUNG, 2011).

A partir desta compreensão, a equipe de Sociologia, mesmo cumprindo a exigência de expor um conjunto de habilidades e competências que os estudantes deveriam assimilar, defendeu e elaborou um currículo centrado na disciplina, demarcando alguns dos conceitos-chave e dos temas norteadores que a especificam. Naquele momento, pretendia-se não "negligenciar a finalidade mais fundamental da educação escolar, que é levar os alunos para além de suas experiências por formas às quais eles dificilmente teriam acesso em casa" (YOUNG, 2011, p.614). Isto é, levar os alunos a se apropriarem das ferramentas e dos fundamentos da ciência (SILVA, 2007). Ainda mais tratando da Sociologia, que é uma ciência que trabalha em uma linha tênue com o senso comum.

Sendo assim, o primeiro passo para a confecção do currículo foi a reunião e comparação dos programas anuais de Sociologia utilizados em sala de aula pelos professores da equipe, destacando-se seus pontos de encontro e desencontro. Observados esses conteúdos, a equipe fez o levantamento de eixos fundamentais do campo mais amplo das Ciências Sociais considerados relevantes para o ensino de Sociologia na Educação Básica. Cultura, Política e Trabalho foram reconhecidos como os campos centrais a partir dos quais trabalharíamos e desenvolveríamos os conteúdos curriculares da disciplina.

No decorrer do processo, definiu-se como estratégia adotar um modelo de "currículo máximo", ou seja, um modelo mais "robusto" em termos de propostas, tendo em vista o compromisso firmado pela Secretaria em proceder a sua discussão e avaliação em fóruns locais e encontros presenciais com demais professores das diferentes regiões do estado ao longo do ano de 2011. 
PERCURSOS DE UMA DISCIPLINA EM CONSTRUÇÃO: CURRÍCULO E IDENTIDADE DO ENSINO DE SOCIOLOGIA NO RIO DE JANEIRO Marcia Menezes Thomaz Pereira

Neste sentido, uma versão mais enxuta, isto é, mínima de fato do currículo, deveria ser resultado de avaliações realizadas a partir da experiência e avaliação posterior de um conjunto maior de professores da rede.

Assim, conforme previsto no planejamento da SEEDUC, os currículos das disciplinas que compunham o projeto para 2011 foram apresentados em "audiências públicas" nos auditórios da Universidade do Estado do Rio de Janeiro (UERJ), no dia $1^{\circ}$ de fevereiro de 2011, primeiro dia letivo do calendário escolar. Cerca de 150 professores de Sociologia da rede pública estadual estiveram presentes nesta audiência.

O evento, para além de constituir uma apresentação formal do Currículo Mínimo, seria a primeira oportunidade de debate público da proposta preliminar. Os comentários à proposta de Sociologia passaram por temas como a necessidade de maior participação em sua formulação, considerando que a equipe estava restrita a apenas seis professores, e o grande volume de conteúdo por bimestre, sobretudo diante do grave quadro de déficit de aprendizado com o qual alunos chegam ao Ensino Médio combinado à reduzida carga horária, em especial, no ensino noturno. Contudo, boa parte das reações dos professores participantes desta audiência fazia referência à proposta política mais ampla na qual esse e outros projetos da SEEDUC estavam inseridos e que impactavam sobre as próprias condições de trabalho dos professores e as condições de ensino e aprendizagem de alunos da rede pública do estado Rio de Janeiro.

Em abril de 2011, enquanto todas as equipes disciplinares trabalhavam no levantamento de referências bibliográficas que pudessem dar suporte aos currículos, aguardando o início da realização dos fóruns e encontros com os professores, a SEEDUC, através de sua Diretora de Pesquisa e Organização Curricular, comunicou a paralisação temporária dos trabalhos. No entanto, no mês de outubro, a página eletrônica Conexão Professor anunciava a seleção de novas equipes para elaboração dos Currículos Mínimos das mesmas disciplinas cujas equipes haviam sido formadas no final de 2010, mas agora sob responsabilidade da Fundação Centro de Ciências e Educação Superior à 
PERCURSOS DE UMA DISCIPLINA EM CONSTRUÇÃO: CURRÍCULO E IDENTIDADE DO ENSINO DE SOCIOLOGIA NO RIO DE JANEIRO Marcia Menezes Thomaz Pereira

Distância do Estado do Rio de Janeiro (CECIERJ). Os membros das equipes paralisadas em abril foram convidados a participar do novo processo. $\mathrm{Na}$ ocasião, toda a equipe de Sociologia se recusou a participar, pois a composição de uma nova equipe para a formulação de um novo currículo adensava um diagnóstico que já vínhamos produzindo acerca do caráter da política de educação do governo do Estado do Rio de Janeiro, bem como dos limites da construção de um currículo consequente com a diversidade cultural e socioeconômica da rede pública, bem como efetivamente democrático.

Desse modo, em outubro de 2011, uma nova equipe e coordenação de Sociologia foram montadas. $\mathrm{Na}$ ocasião, os professores optaram partir da revisão e aproveitamento do currículo organizado pela equipe anterior. No entanto, seguiram a orientação da SEEDUC na formulação do currículo em habilidades e competências, retirando do produto final os conceitos-chave e os temas norteadores que visavam auxiliar aos professores na elaboração dos seus planos de aula. Esta nova equipe, composta por três professores da rede e um coordenador, realizou o trabalho de revisão, produzindo a versão mais enxuta do Currículo Mínimo.

Tal trabalho de reorganização foi validado por meio de duas escutas públicas. Os questionamentos sobre a natureza do processo de construção do currículo, sobre seu conteúdo, bem como da política na qual ele se insere, também deram 0 tom desses encontros. No entanto, um dos maiores questionamentos em torno desta versão ainda estava por vir. Elaborado a partir da carga horária vigente para as aulas de Sociologia na matriz curricular de 2011 para o Ensino Médio regular, em menos de uma semana após seu lançamento, a SEEDUC anunciou a redução da carga horária da disciplina para o ano seguinte. Este evento foi duramente criticado e culminou com a renúncia e saída do coordenador da nova equipe do Projeto. Mesmo diante desse fato, o Currículo Mínimo na versão 2012 se manteve inalterado e é ainda hoje o programa curricular de Sociologia na rede.

As propostas curriculares oficiais, e mesmo o currículo que é posto em prática nas escolas, são sempre constituídos por processos de 
PERCURSOS DE UMA DISCIPLINA EM CONSTRUÇÃO: CURRÍCULO E IDENTIDADE DO ENSINO DE SOCIOLOGIA NO RIO DE JANEIRO Marcia Menezes Thomaz Pereira

recontextualização (LOPES e MACEDO, 2006). Entendendo a escola como um campo de reprodução, mas também de resistência, produção e possibilidade de emancipação, nos processos de recontextualização, no interior dessas instituições, há espaços para ressignificar, reelaborar, por exemplo, os princípios instituídos e prescritos oficialmente pelo Estado. Especialmente tratando da disciplina Sociologia, dadas as características de sua trajetória e a especificidade desta ciência, esses processos de recontextualização aparecem de forma bastante evidente - e são sobre eles que devemos nos debruçar.

\section{CONSIDERAÇÕES FINAIS}

Reiterando o que foi colocado no início desse texto, as peças curriculares são expressão da própria trajetória da disciplina e a configuração da sua identidade que vem sendo desenhada a partir de uma teia de relações não premeditadas entre os agentes que formam este processo: professores, estudantes, universidades, gestores da educação, governo, etc. O Currículo Mínimo, diferente das peças curriculares que o antecederam, tem tido ampla repercussão, sendo alvo de críticas em múltiplos aspectos, não apenas na rede estadual, mas no cenário nacional. Se por um lado reflete os desafios que ainda precisamos percorrer e ajustar, por outro sugere que há hoje, no contexto de - ainda que incerta - obrigatoriedade da disciplina, um acúmulo mais sistematizado para refletir sobre o tema e, sobretudo, uma comunidade mais organizada e voltada para pensar e defender a Sociologia enquanto disciplina escolar.

O desenho da sua identidade tem se mostrado cada vez mais um elemento imprescindível para o reconhecimento do seu papel e do seu lugar dentro e fora da escola, além da sua valorização enquanto disciplina escolar. "Que Sociologia é essa que vem sendo trabalhada?", "o que é a Sociologia no Ensino Médio?", "o que a diferencia e especifica em relação às demais disciplinas?", "quais os sentidos e os objetivos desta disciplina na formação escolar?" são ainda perguntas frequentes, tanto nas escolas quanto no meio 
PERCURSOS DE UMA DISCIPLINA EM CONSTRUÇÃO: CURRÍCULO E IDENTIDADE DO ENSINO DE SOCIOLOGIA NO RIO DE JANEIRO Marcia Menezes Thomaz Pereira

acadêmico. Buscar algumas respostas é ainda uma tarefa que se coloca para professores/pesquisadores. Partindo do pressuposto que a identidade é um processo social em permanente construção e que se desenvolve a partir da dinâmica das relações sociais, não podemos pretender atingir um "ponto de chegada" que defina uma identidade essencializada. Mas trazer elementos que permitem pensar a configuração e a inserção desta disciplina na escola e que possam contribuir para apontar alguns desafios, mas também possibilidades para a sua consolidação na formação escolar. Sem dúvida, pensar os currículos propostos bem como os conteúdos e as metodologias que vêm sendo acionados nas diferentes salas de aula parece ser um caminho fértil no cumprimento de tal tarefa.

\section{REFERÊNCIAS}

CONTERATO, S. (Org.). A Profissão de Sociólogo e a Sociologia no Ensino Médio. Rio de Janeiro: APSERJ, 2006. In: LOPES, A.C.. Conhecimento escolar: ciência e cotidiano. Rio de Janeiro. Ed. Uerj, 1999.

LOPES, A. C.; MACEDO, E. Nota introdutória: reconfigurações nos estudos sobre políticas de currículo. Currículo sem Fronteiras, v.6, n.2, pp.5-9, Jul/Dez 2006.

PEREIRA, M.M.T. A construção social da identidade da Sociologia como disciplina escolar: que Sociologia é essa? 2013. Dissertação (Mestrado em Ciências Sociais) - Universidade do Estado do Rio de Janeiro, Rio de Janeiro, 2013.

RAMOS, M. N. Pedagogia das competências: autonomia ou adaptação? São Paulo: Cortez, 2001.

SILVA, I. F. A sociologia no ensino médio: os desafios institucionais e epistemológicos para a consolidação da disciplina. In: Revista Cronos, NatalRN, v. 8, n. 2, p. 403-427, jul./dez. 2007.

YOUNG, M. O futuro da educação em uma sociedade do conhecimento: o argumento radical em defesa de um currículo centrado em disciplinas. Revista Brasileira de Educação. v. 16 n 48, set-dez. 2011. 


\section{DOCUMENTOS OFICIAIS}

RIO DE JANEIRO (Estado). Reorientações Curriculares - Sociologia.

Secretaria de Estado de Educação do Rio de Janeiro, 2006.

. Proposta Curricular: um novo formato - Sociologia.

Secretaria de Estado de Educação do Rio de Janeiro, 2010.

. Currículo Mínimo Sociologia 2011. Secretaria de Estado de Educação do Rio de Janeiro, 2011.

. Currículo Mínimo Sociologia 2012. Secretaria de Estado de Educação. Rio de Janeiro, 2011. 